\title{
STAFF TRAINING AND DEVELOPMENT - AN EXPRESSED NEED
}

\author{
by \\ Joanne Locke
}

\section{Definition and Need for Continuing Education Programs}

Staff training and development, an aspect of continuing education, has long been recognized as an essential process in the practice of the library and information science profession. This expression of need by both the employee and the employer is a central point of the literature today and parallels that of over thirty years ago when Cyril O. Houle cited four specific areas of development required by the practicing professional in his article entitled "The Role of Continuing Education in Current Professional Development." These include: 1 ) keeping up with new knowledge relating to one's profession; 2) establishing mastery of new conceptions of that profession; 3) continuing the study of basic disciplines which support one's profession; and 4) growing as a person as well as a professional. (Houle 263-64)

Increasingly, this expression of need is being responded to today by programs that speak to permanency and priority as revealed in the two articles in this issue and by numerous others in the literature.

Lifelong learning compels us to update our education and increase knowledge in all facets of our lives. As Richard House states: "The world is changing so rapidly that individuals must live in several different worlds during their lifetimes. One generation can no longer pass along to the next generation what is needed to get along in the world. The recognition that no education can last a lifetime is changing the way our society thinks about education and learning. Education is now regarded as a continuous process and is needed in most every aspect of an adult's life." (Gerber and Tees 59)

More specifically within the library and information profession, Elizabeth Stone's 1969 definition continues to provide a sound basis for current definition. In her view, continuing education encompasses “... all activities and efforts by the individual to upgrade his knowledge, abilities, competencies, and understanding in his field of work or specialization so that he can become a more effective professional and be able to handle responsibilities of greater scope and accountability." (Stone 21)

\section{Why Programs are Necessary}

While the literature increasingly speaks to the need for continuing education programs and the benefits they offer to both the employee and the employer, the Association of Research
Libraries (ARL) SPEC flyer on staff training and development reveals some interesting findings. A compilation of survey responses from fifty member institutions indicates that:

- 56 percent of respondents have a formal library program in place;

- of the 44 percent that did not, slightly more than half [were] planning such a program;

- 73 percent have a budget for staff training and development;

- the typical staff development budget does not constitute a line item in the library's overall budget but consists of a series of funds made available on an as-needed basis; and

- 37 percent have programs that were established more than ten years ago, while 27 percent of respondents have relatively new programs established within the past one to three years. (ARL)

It appears evident that despite an expressed need, not every organization has initiated a staff development program. However it is encouraging to note that many have plans for programs to be initiated in the future.

The combined statistic of those with newly established programs and those planning a program emphasizes the increasing recognition of need. Many factors contribute to this need for formalized programs in staff training and development. One of the most obvious indicators is the increasing multidisciplinarity of the library and information science profession. The profession, characterized by a convergence of the traditions of library and information science as we know them, together with the disciplines of management, communications, computer science and education, speaks to Houle's stated requirement of knowledge in complementary disciplines. This is further exacerbated by the increasing complexity of the organizations and users being served.

The impact of rapidly developing technologies is having multiple effects on service to users; most prominently the perception that all information is instantaneously available and free. This perception, fueled by users' observations of their surroundings in terms of Internet services, talk of virtual libraries, global knowledge and information transfer, fails to consider the complexities of information organization and access. Information professionals are expected to be conversant with these technologies, yet how can they be if not provided with opportunities for training and development? 


\section{Benefits and Constraints in Offering a Program}

Organizations that do participate in offering established programs of training report that benefits are immeasurable. Not only are users supportive of the many services based on their positive experiences, but also staff tends to be more self-confident and to exhibit an enhanced ability in dealing with diverse situations and problem solving. This has increased productivity and a greater loyalty to an organization that has shown a willingness to invest in their employees and their ongoing development. Continuing education further serves to allow professionals to better adapt to the changing technologies. When staff is involved in the training programs and contributes to the effective performance of each individual, it demonstrates that the library supports the growth of its librarians. A library can benefit greatly from "systems thinking", one of the basic aspects of Peter M. Senge's philosophy. This means employees "learn to focus upon the whole of the organization rather than the individual parts." (Callahan and Watson 377) The end result is an overall strengthening of the entire organization.

Despite the numerous and stated advantages, several obstacles make it difficult for the establishment of and participation in staff training and development. As with many initiatives, funding is a primary stumbling block. In a time of shrinking budgets, and haunted by an expectation to do more with less, organizations justify that they cannot always set aside funds to support such an endeavor. Employees feel that while this is best for their professional development because it serves to improve or enhance their contribution to the organization, their budgets do not always allow funds to be set aside for this purpose.

In order to meet job demands, many professionals are spending more time at work or are faced with family responsibilities that result in less time for them to attend courses outside of work. While many organizations are happy to provide release time for staff training and development, many employees are reluctant to take this time, the reason being that while away, much of their work accumulates. Upon their return, they must work longer hours to catch up.

\section{Methods of Offering a Program}

To overcome the above-mentioned difficulties, organizations must first recognize and appreciate the benefits both to the institution and the employees. Secondly they must make a commitment to invest in the necessary investigation and planning process that is required in establishing a program that is viewed as an integral component of the organization's being. Once adopted, there are many methods of continuing education, all or some of which can be incorporated into a program.
The literature reveals that short workshops are usually preferred over long-term, extensive courses. Professionals tend to recognize a gap and work to fill it as efficiently and unobtrusively as possible. In-house training, either through bringing in an expert to conduct a seminar or workshop or crosstraining which involves one staff member attending a workshop and in turn offering that workshop to fellow colleagues, is often cited as an effective method of instruction which reduces both collective costs and travel time. Additional effective means of development include less formal methods such as reading the professional literature; participating in discussions (either traditionally or electronically), and teaching oneself new skills. Just as technology has in part created the necessity for increased training and development so has it facilitated delivery. Teleconferencing, listservs discussions and Internet-based courses allow for flexibility while reducing costs and in some cases travel time.

The two libraries reporting in this issue have responded to the need for staff training and development through the establishment of programs that serve as a foundation for further growth. Both organizations exhibit commitments to this growth that will help them to meet the challenges of the future.

\section{Sources Cited}

Callahan, Daren and Mark Watson. "Care of the Organization: Training and Development Strategies." Journal of Academic Librarianship (September 1995): 376-81.

Gerber, Ellen and Tees, Miriam. "Continuing Education and Professional Developments." In The Program of the Special Libraries Association: Proceedings of a World Confernece on Continuing Education for the Library and Information Professions. August 13-16, 1985. New York: K.G. Saur, 1985. Houle, Cyril O. "The Role of Continuing Education in Current Professional Development." ALA Bulletin 61 (March 1967): 259-67.

Stone, Elizabeth W. Factors Related to the Professional Development of Librarians. Metuchen, NJ: Scarecrow Press, 1969.

Association of Research Libraries. Office of Management Services. Staff Training \& Development. SPEC Flyer 224. Washington, DC: Association of Research Libraries, 1997. 